\title{
PacifiCorp 2009 Competition
}

\author{
Mark Moore, 2009 PacifiCorp Mentor
}

It wasn't the World Series, or NASAR, or the US Open, but it was a competition and a fine one at that. Three academic teams met at this year's AECT conference in the finals of the annual PacifiCorp competition. The teams had been working on a problem centered on the practical training needs of a fictitious company. Through two rounds with a panel of judges, they had revised and written their base proposals, ones they hoped blended the best of academic learning theory with a solution that would deliver for a company seeking to compete in today's marketplace.

The final presentations, given directly to the judges who acted as the fictitious company's Board of Directors, gave the teams one more chance to drive home their points. Each used key elements of learning and development to answer the challenges presented in the problem statement. The participants, all graduate students, chose hand outs, PowerPoint slides, and innovate idea mapping to help the judges visualize their concepts. In the end, the team from Emporia State (Kansas) beat out great presentations from Florida State and Utah State. The judges noted it was the tightest competition they had ever witnessed.

Who benefits from such a competition? Certainly, the students involved gain a better understanding of the theories surrounding learning and development, adult education, and program design. Working through the papers presented, from abstract to final form, provides an opportunity to expand on the theories learned in classes and research. The goal is to provide a practical solution to the problem stated that is based on sound theory and research. In fulfilling this, the student competitors have the chance to carry that learning forward to their own classrooms as they teach others. This can only serve to increase the quality of programs training others in education and instructional design.

Ultimately, the biggest beneficiary is corporate America. When programs in our universities are designed specifically with the practical needs of a competitive marketplace in mind, the result is a better product overall. When the bottom line is scrutinized and budgets are tight, only training programs with a clear return on investment will stand up. And those programs will be developed by people such as the six who competed in this year's finals.

When Dr. Kaminski, my advisor from grad school days, approached me early in 2009 about being a team mentor, I readily agreed to participate. In true "rookie" fashion, I didn't know what to expect. My team (Utah State) was comprised of two $\mathrm{PhD}$ candidates. My role was to bring a practical view to the team, based on my experience training in the corporate and professional world. We exchanged e-mail and phone calls over the summer, working on revisions of their core document. Once they made the finals, arrangements were made to meet in Louisville at the AECT conference.

All the work to that point was now compressed into a few hours. We had exchanged comments on the final slide deck and met the day of the competition in one of the vacant rooms. The team practiced, I commented, and we fine-tuned the presentation. They showed a clear com- mand of their material during the finals, but we fell just a little short of the winning team, Emporia State. As we recapped the event, we all learned from the experience and I agreed to participate as a mentor again in 2010, where my approach to the 2010 team will be a little different.

While everything leading up to the final presentation has a distinctly academic tone to it, the final competition is won or lost based on how practical the solution is and how it would be implemented if selected. Companies who choose to implement training do want tangible results, either by direct contribution to the bottom line or by avoiding future costs and increasing or keeping margins strong. Keeping this in the forefront during my next round with a PacifiCorp team, is the very thing that will make the academic side better.

Our universities face the challenge of preparing people to contribute, largely in a corporate setting. Sitting in on the planning session for the 2010 competition and reading the problem statement only reinforces this thought in my mind. I would love to see two dozen teams from around the country step up and take the challenge by presenting an abstract. This can only serve to improve our approach in academia and to provide the corporate world with stronger opportunities to meet the ever-changing landscape. Building solutions with a practical connection to real-world needs and problems is the heart of the PacifiCorp challenge. Let's band together, rise up, and meet it in 2010 and beyond.

For a full description of this year's problem, see the following page. 